\title{
Inverse Methods and Integral-Differential Model Demonstration for Optimal Mechanical Operation of Power Plants - Numerical Graphical Optimization for Second Generation of Tribology Models
}

\author{
Francisco Casesnoves* (Researcher, Tallinn University of Technology, Tallinn, Estonia)
}

\begin{abstract}
Stepping forward from a previous conference contribution, the article focuses on extension of inverse problem algorithms to integral-differential modelling and formal/strict demonstration of graphical-optimization method. It shows evident-mathematical and 3D-imaging proofs of the graphical optimization method with $L_{1}$ Norm simulations and algorithms. At present, Linear/Nonlinear Optimization mathematical methods constitute the choice of preference in getting improvements for erosion and corrosion simulationsdeterminations in general tribology, biotribology and tribocorrosion. The method(s) developed are classical numerical optimization settings for objective functions, programming optimization and simulations, and special software for imaging in 3D. Results are diverse and the range of their applications is wide. First, the article provides a definite formal demonstration of the nonlinear graphical optimization both in numerical results and in imaging. Then, the authors propose the development of programming optimization and mathematical proofs-algorithms of the integral-differential model for various models. Subsequently, an overview of stochastic erosion methods based on Markov Chain is presented in the article. Finally, the second generation of tribology models is defined and conceptually explained. To summarise, the article comprises new findings towards modernization of tribology, biotribology and tribocorrosion models, gathering innovative research branches for future extension of the mathematical modelling progress. The results can be applied to both general techniques and mechanical engineering. The analytical and numerical demonstration of the integral-differential model constitutes a key point and essential result of the research. Extension to electromagnetic and electronic models of these methods is also considered feasible and practical.
\end{abstract}

Keywords - Engineering reliability operational probabilities; Functional power plants; Inverse problem theory/applications; Nonlinear optimization; Power engineering.

\section{INTRODUCTION AND BASIC CONCEPTS}

The concept of Inverse Problems (IP) [1], [2], became significantly important over the past century and was extended to a large number of branches of science and engineering. In the past, trial and error methods were the main technique to improve or develop mathematical formulation. However, it was soon understood in practice that empirical data should be used to make the configuration of the mathematical model rather than to adapt the formulation directly on the experimental measurements through successive proofs/intends. In plain language, IP abstract idea is applicable to most of the human/animal knowledge branches, namely, from science, engineering, economy to philosophy or sociology. Any observer/electro-mechanical system is surrounded and continuously receiving signals, both mental (biologicalcognitive case specifically) and physical, with amounts of information/data from an extensive number of sources. These intense flows of information are formed by signals of different nature, from electromagnetic waves/fields to social structures, emotional perceptions, market-economy fluctuations, radiological imaging shapes for medical diagnosis, chemical reaction at lab, erosion experiment at lab, etc. Each possesses a specific type of records. IP technique rationale is based on the usage of these empirical data to perform an approximated analysis of the emitting real source configuration/ characteristics, and if it were possible, to determine precise algorithms and computational analysis of them - which is usually done using applied mathematical methods. The obsolete, although not in all cases, rather complementary forward method was to try in consecutive trials to validate any algorithm functionality through the insertion of the received database within any kind of tentative equations [1]-[6].

In this situation of study advances developed in the 20th century, a number of algebraic methods arose to match large series of equations over the experimental database. The stage was similar for illustrating the point with an instance to the 19th century, with the high-level/hurdles for the mathematical analysis in differential equations, i.e., researchers focused on finding the precise analytical solutions before the discovery of numerical methods that guided them to useful technical time saving in applied mathematics.

Later on, mathematical formulations in science and engineering became so large and diverse that the algebraic methods appeared to be insufficient to carry out accurate IP methods in practice - the computers were the necessary instruments to perform such large-scale computational work. Therefore, the development route of IPs was linked since that stage to computational methods and extensive numerical analysis [7]-[11]. The number of databases necessary to develop new formulation in science and to improve

\footnotetext{
*E-mail: frcase@ttu.ee
} 
mathematical methods was the routine work load in standard investigation. An important branch of mathematics, both theoretical and applied, linked to the IP theory, was optimization. Optimization methods have experienced a vast expansion all over any branches of engineering and technology because the continuous requirement in research and industry is to obtain an accurate link between any model and the variable empirical data with/without direct application of IP recipes. Therefore, all these concepts are specifically applicable to energy industry since power engineering constitutes a point of convergence for multidisciplinary branches of engineering.

Today, in power engineering and tribology up to quarter of all the tube failures at the coal-fired power plants is caused by the erosion-corrosion wear at the elevated temperatures. Tube replacement accounts for up to $75 \%$ of the total downtime of such plants, increasing the energy production costs up to $54 \%$. The erosion action is due to the ash constituents, such as quartz $\left(\mathrm{SiO}_{2}\right)$, corundum $\left(\mathrm{Al}_{2} \mathrm{O}_{3}\right)$ and iron oxide $\left(\mathrm{Fe}_{2} \mathrm{O}_{3}\right)$, whereas the most severe wear is caused by quartz [3]. For ash with a high quartz content, the gas flow velocities inside the tubes have to be limited to $12-13 \mathrm{~m} / \mathrm{s}$, despite the decrease in the power plant production efficiency (for less erosive ash, the gas flow velocities of $18-20 \mathrm{~m} / \mathrm{s}$ are allowed ) [12]. In its turn, the corrosion component of the wear process is induced by the temperatures inside the tubes. The typical range is from $380^{\circ} \mathrm{C}$ to $538{ }^{\circ} \mathrm{C}$. In addition to its absolute value, the cyclic character of heating should be taken into account as it may cause the spallation of the oxide films and thus accelerate the wear.

Statistically, a rate higher than $90 \%$ of mechanical machine failures is related to fatigue, friction, stress, and wear [2], [3], [5]. The causes of degradation, in general, are wear, corrosion, oxidation, temperature, gas particle size/velocity, and any combination of these factors. Mathematical modelling is essential for determination of engineering probability of failure of any mechanical or electromechanical system. In fact, there are a number of mathematical models for erosion, biotribology, tribocorrosion, corrosion, and combinations of these phenomena.

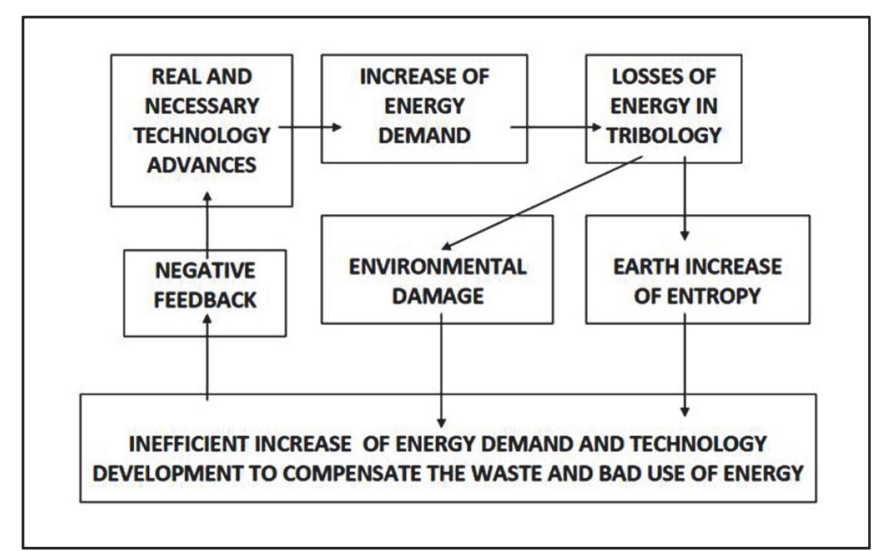

Fig. 1. Energy optimal performance related to requirement for tribological optimization of mathematical models in power plants. It is presented in the flow chart both the meaning of the necessary technological advances and the concept of inefficient use of energy. The importance of entropy icrease is emphasized.
A large-scale statistical determination of worldwide energy consumption, due to Tribological origin [13], [14], sets the approximate rate of $23 \%$ loss of energy caused by wear and friction. This fact implies serious consequences in engineering, economy, and environmental science engineering. What is more, the loss and/or ineffective use of energy cause a thermodynamical increase of entropy on the planet, with subsequent consequences for environmental damage increment rate along the years/decades. In other words, as illustrated in Fig. 1, the reduction of the rate of entropy increase on the earth is directly related to losses of energy, which do not arise from practical use.

So far, the trial-and-error approach has been applied in the industry [4]-[19]. However, field tests are very expensive, take much time and are hard to track and evaluate. Therefore, it is important to develop mathematical models in order to estimate and predict the erosion-corrosion rates [7].

The present article deals with the subsequent steps following previous publications of mathematical models for power plants in erosion, corrosion, and tribocorrosion. A number of models have been optimized using computational software and presented with database of laboratory description and a series of 2D-3D graphical works for sharp learning [19]-[23].

The first section of the article is the essential part of the previous paper, which is necessary to understand the evolution of concepts for the acquisition of the new one. It focuses on the development of the concept of the integral-differential model/method of the second generation of tribology mathematical models. The present research provides sharp examples of the upper-threshold passing from finite/discrete mathematics to infinitesimal calculus in integral-differential models. Markov chain methods for stochastic optimization of erosion in hardface are also explained in brief.

Results comprise mathematical formulation/models for optimized erosion, proof of fitting residuals, graphs of global minima of objective functions and 3D special graphical optimization. For graphical optimization, a subsequent step forward set on a carbon energy model with objective function inserted explicitly in the surfactal plot is carried out. This way, the complementary section of the paper intends to explain a new generation of mathematical modelling in engineering of general tribology, based on functional models.

\section{MATHEMATICAL AND COMPUTATIONAL METHOD(S)}

The research methods focus on practical optimization and nonlinear inverse problem applications in erosion models useful for power plants with mechanical systems and machinery. The selected models are appropriate to be applied for wear and abrasive wear in some components - and the most important part of the present research is the demonstration of the technique applicable to a large number of models.

In general, most of the tribological models, mainly for abrasive wear erosion, are nonlinear equations, since their research origin had to be fitted on an extent empirical database. This fact has consequences in the choice of the most appropriate subroutines for optimization. In the present research, some of them are implemented to obtain accurate optimization of models and their usage is sharply presented in 
numerical tabulation and 2D-3D graphical optimization images [7].

In other words, let us suppose that the obtained laboratory measurements data, $D_{i}$ are trustworthy statistically and the objective is to fix the optimal parameters of a selected model, $M$, by using IPs with nonlinear optimization methods. What is meant here is an extremely simple example of the standard methodology.

If those data numbers $D_{i}$ corresponded exactly to the model equation $M$, we would have the equality:

$D_{i}=M_{i}$ (function of $x, y, z, \ldots$ parameters of model),

$x$ could be particle speed, $y$ - density of hardface, etc.

For every measurement $M_{i}$ inserted within the model equation, the exact result would be equal to $D_{i}$. However, this is totally unreal in engineering practice, including power engineering, i.e., in the attempt to set the model, initially we obtain:

$D_{i} \neq M_{i}$; and it is strictly necessary to carry out approximations for $x, y, z, \ldots$ etc., so passing $M_{i}$ on to the left side,

$D_{i}-M_{i} \neq 0$, as mentioned, $D_{i}$ are lab fixed numbers,

and $M_{i}=M_{i}(x, y, z, \ldots$ parameters of model to be optimized $)$ Therefore, the very basic IP methods, in plain language, are to make software/algorithms to find the solution of the equation: minimize,

$$
\sum_{i=1}^{i=N}\left\|D_{i}-M_{i}(x, y, z, \ldots)\right\|_{2}^{2} ; \text { with } M=\text { selected model; }
$$

with the objective to make,

$D_{i} \cong M_{i}$ (approximately equal),

and NOT $D_{i} \neq M_{i}$;

This example serves as an introductory illustration for sharp learning of the following research sections [22]-[25]. The square power in this kind of formula ( $L_{2}$ norm formally) is done, among many mathematical and optimization reasons, to guarantee all the curves to be at the positive quadrants in 2D and $3 \mathrm{D}$. $L_{1}$ norm, which can be seen as the absolute value of the objective function, is explained in Section IV with a formal proof of graphical optimization algorithm for a classical model. $L_{1}$ norm can be applied in the so-called Chevyshev Multiobjective Optimization and reads:

minimize,

$$
\sum_{i=1}^{i=N}\left|D_{i}-M_{i}(x, y, z, \ldots)\right|_{1} ; \text { with }
$$

$M=$ selected model;

The previous least-squares method is more commonly implemented in practice; however, to date the choice for objective functions has increased in options and sub-options extensively [26]-[28].

\section{COMPUTATIONAL AND PROGRAMMING INVERSE NONLINEAR OPTIMIZATION RESULTS}

The present section discusses simulations and optimization series of several models. Each model simulation has the same structure, namely, numerical simulation, graphical simulation, and nonlinear optimization. Experimental values are taken from the laboratory of Tallinn University of Technology (TUT) and are real - sometimes approximations are necessary. The mathematical and computational method designed for showing inverse nonlinear optimization and 3D-Graphical Nonlinear Optimization is almost the same for all the model equations selected. General methodology is more significant than the type of models selected for power plant erosion/corrosion. The Hutchings model was originally designed for plastic deformation. There are a number of formulas related to Hutchings model, from simplest to the most complicated ones [9]. The initial formula to be simulated, for the sake of sharpness, is

$$
E=\frac{K \rho U^{2}}{2 H},
$$

where $\rho$ is the density of the material being eroded, $U$ is the initial particle velocity and $H$ is the target surface hardness. $K$ represents the fraction of material removed from the indentation as wear debris and is also known as the wear coefficient. What is going to be optimized at first is the value of $K$ that can be interpreted as a measure of the efficiency of the material removal process. In other words, the first step is to determine the optimal value of $K$ for a random range around an interval of experimental measurements of $\mathrm{SO}_{3}$ material based on lab tribotests of TUT, which is direct application of inverse methods. The second step is to simulate the model for a range of hardness and impact velocities in interval around the experimental velocities of abrasive impact particles [29], [30]. All these data are set in Table II. The objective function is a multiobjective least squares with $L_{2}$ norm. The experimental hardness is set for optimization ( 31 measurements), and the $K$ wear coefficient is the variable to be determined.

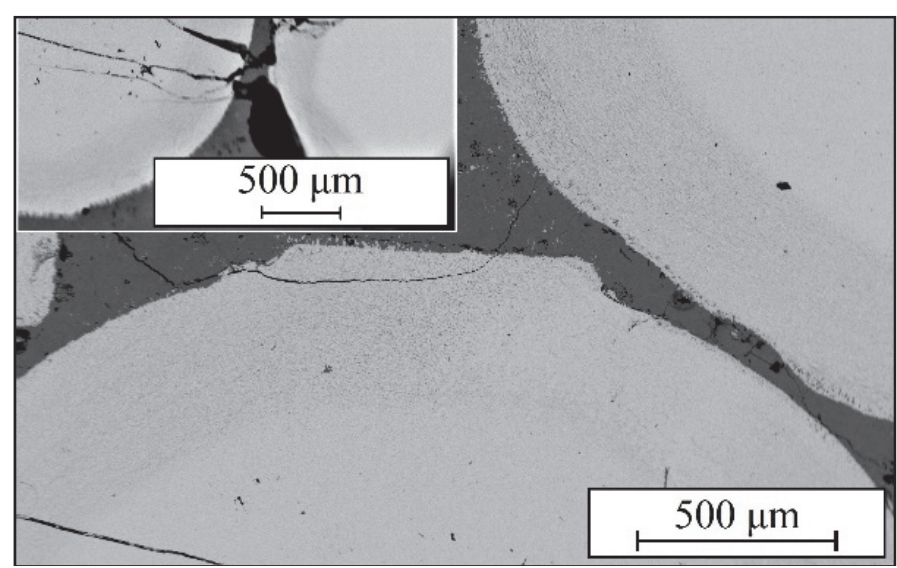

Fig. 2. Experimental sample from the laboratory of Tallinn University of Technology, showing the microstructure of the studied hardfacings. Composite hardfacing with 50 vol. \% spherical WC-Co reinforcement. The numerical hardface data that were implemented in (1) and (2) for optimization correspond to this kind of material. 


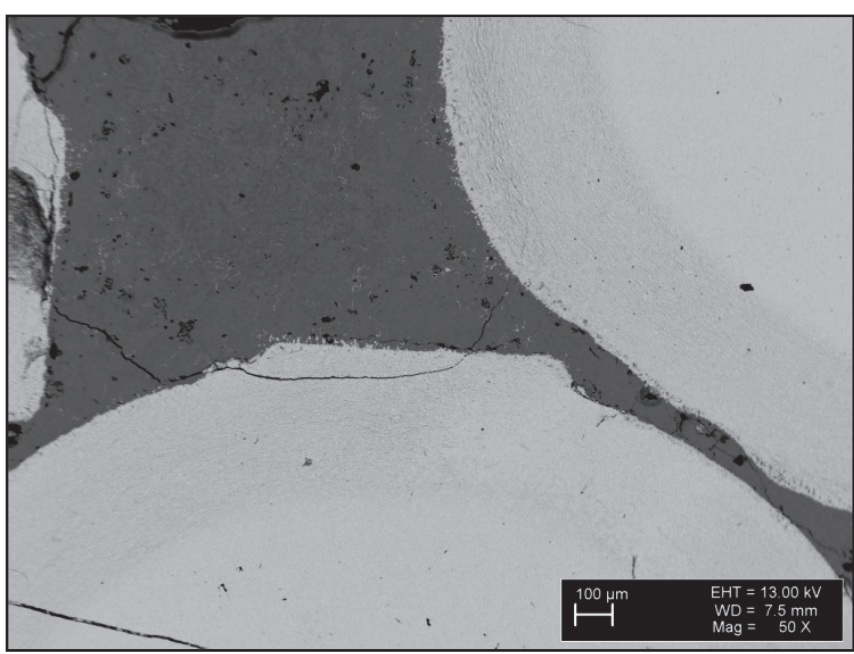

Fig. 3. Enhanced, experimental sample from the laboratory of Tallinn University of Technology, showing the microstructure of the studied hardfacings. Composite hardfacing with 50 vol. \% spherical WC-Co reinforcement. The numerical hardface data that were implemented in (1) and (2) for optimization correspond to this kind of material. The interface is sharply shown in upper right circumference around the interior hardface surface.

TABLE I

NUMERICAL VALUES OF HARDFACE HARDNESS FROM LAB EXPERIMENTAL MEASUREMENTS

\begin{tabular}{|c|c|c|}
\hline \multicolumn{3}{|c|}{$\begin{array}{c}\text { Examples of experimental data for model development [Laboratory at } \\
\text { Tallinn University of Technology, Estonia] }\end{array}$} \\
\hline $\begin{array}{c}\text { Number of measurement } \\
\text { Total measurements of hardface }= \\
31\end{array}$ & \multicolumn{2}{|c|}{ Hardness, mpa } \\
\hline 1 & \multicolumn{2}{|c|}{1653} \\
\hline 2 & \multicolumn{2}{|c|}{1653} \\
\hline 16 & \multicolumn{2}{|c|}{1881} \\
\hline 22 & \multicolumn{2}{|c|}{1954} \\
\hline 29 & \multicolumn{2}{|c|}{2060} \\
\hline $\begin{array}{c}\text { Experimental lab data for } \\
\text { optimization }\end{array}$ & $\begin{array}{l}v=40 \mathrm{~m} / \mathrm{s} \\
\quad \text { erosion } \\
=3 \mathrm{~mm}^{3} / \mathrm{kg}\end{array}$ & $\begin{aligned} & v=80 \mathrm{~m} / \mathrm{s} \\
& \text { erosion } \\
= & 18 \mathrm{~mm}^{3} / \mathrm{kg}\end{aligned}$ \\
\hline
\end{tabular}

Note: Composition of alloy-reinforced experimental samples is $70 \mathrm{FeCrBSi}$, 30 WC-Co whose data were implemented for optimization of $K$ wear coefficient in (2) [Laboratory at Tallinn University of Technology].

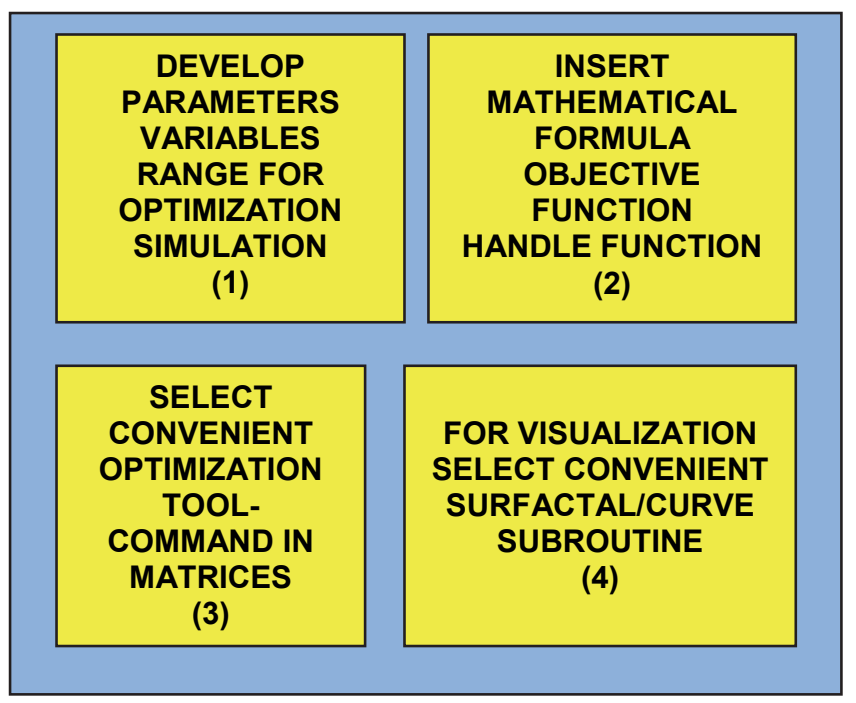

Fig. 4. Flow chart of a graphical optimization program (basic).

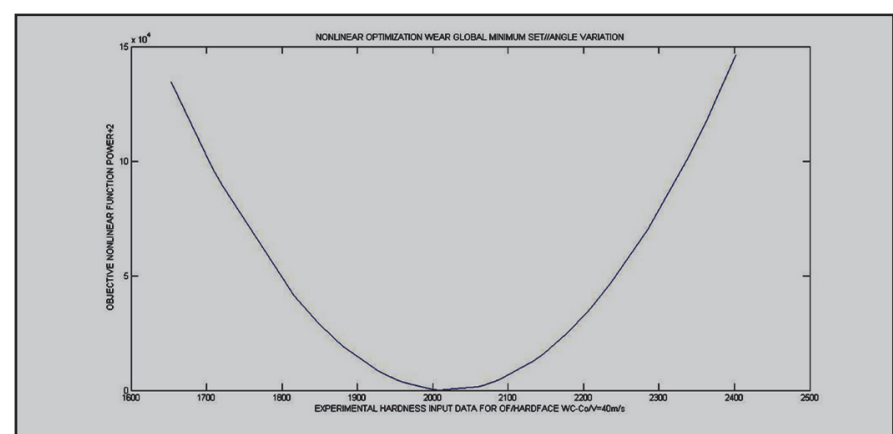

Fig. 5. Objective function (OF) nonlinear optimization results for Table I and Eq. (2) model, Matlab 2009-12. The impact velocity is $40 \mathrm{~m} / \mathrm{s}$. Results are acceptable with a Global Minimum sharply determined and running time is lower than a second.

TABLE II

NUMERICAL DATA OBTAINED FROM NONLINEAR OPTIMIZATION OF (2)

\begin{tabular}{|c|c|c|}
\hline Search point & $\begin{array}{c}\text { Optimal } K / \text { hardness } \\
\text { value } \\
\text { (inverse method) } \\
v_{\text {particles }}=80 \mathrm{~m} / \mathrm{s}\end{array}$ & $\begin{array}{c}\text { Residual of objective function } \\
\text { (OF) }\end{array}$ \\
\hline$x=20$ & $0.7945 / 2008$ & $1.6135 \cdot 10^{3}$ \\
\hline$x=-1$ & $0.7945 / 2008$ & $1.4735 \cdot 10^{3}$ \\
\hline Comments & $\begin{array}{c}\text { Acceptable result for optimization of low residual of OF } \\
\text { global minimum exact for any search point, even } \\
\text { negative points }\end{array}$ \\
\hline
\end{tabular}

Note: Particle velocity is $v=80 \mathrm{~m} / \mathrm{s}$. Experimental values, impact velocity, material density, and all parameters implemented are from laboratory measurements results.

The subsequent simulations are intended to verify numerically the goodness of $K$ wear coefficient that was obtained by optimization, first, for $v=40 \mathrm{~m} / \mathrm{s}$, and then for $v=80 \mathrm{~m} / \mathrm{s}$. This is performed with software for 3D graphical simulation [31]-[38]. Figure 3 shows the simulation of $K$ value for a range of hardness and erosion around the experimental laboratory data. The range of hardness is in the interval $[1600 ; 2500]$, and the range of simulated erosion in $z$ axis. The cursor search verifies the data of optimal $K$ value of 0.5297 , since it indicates the approximation for that value at the optimization values obtained for an erosion magnitude of 3 $\mathrm{mm}^{3} / \mathrm{kg}$. Cursor indicates a magnitude $K=0.5274$, for erosion rate around 3 and hardness around 2000, even more accurate values can be reached with more tentative search at $3 \mathrm{D}$ graphics.

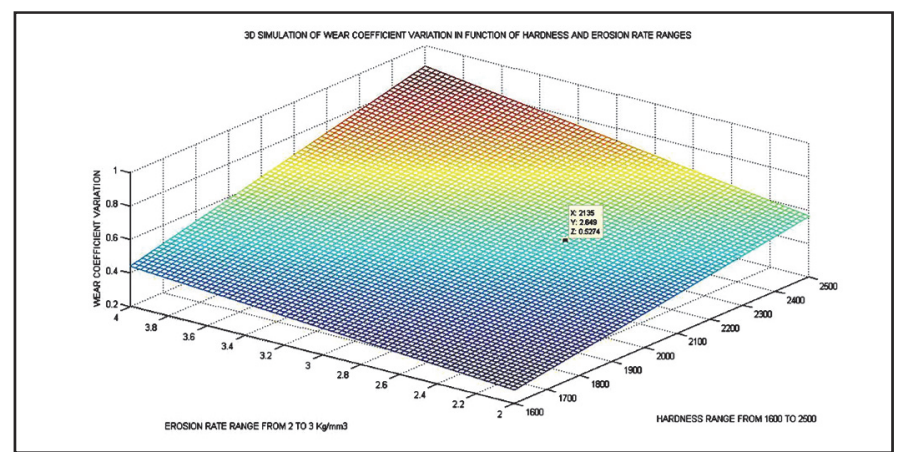

Fig. 6. 3D surfactal simulation results for Table III and Eq. (2) model. The impact velocity is $40 \mathrm{~m} / \mathrm{s}$. Results are acceptable with a Global Minimum sharply determined by cursor that verifies the optimization software results. Matrices of imaging are $75 \times 75$. 
Following the same type of simulation, the next is to verify the value of the $K$ coefficient for $v=80 \mathrm{~m} / \mathrm{s}$. Figure 5, pictured with cursor values inset, demonstrates the simulation for this velocity and a range of erosion around experimental values of lab [2], [5]. The accuracy of the simulation is determined by cursor K magnitude, which is 0.7919 almost equal to the optimal value of 0.7945 .

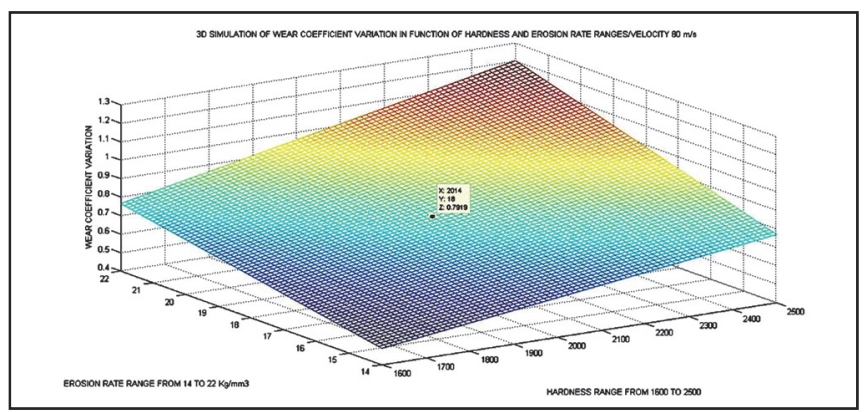

Fig. 7. 3D surfactal simulation results for Table IV and Eq. (2) model. The impact velocity is $80 \mathrm{~m} / \mathrm{s}$. Results are acceptable with a Global Minimum sharply determined by cursor, 0.7919, which verifies the optimization goodness software results. Matrices of imaging are $75 \times 75-$ with Matlab it is possible to reach $1000 \times 1000$ dimensions, with Freemat the maximum size is nearby $400 \times 400$ for acceptable running image-performance time.

The next proof of simulation is done with the same experimental data but a more precise formulation derived from the previous model, namely,

$$
E=\frac{K \rho[V \sin \alpha]^{2.5}}{H},
$$

where all the parameters are the same of (2) but the impact angle alpha and the power of the velocity are different. This model was designed specifically for cutting wear, in such a way that the power of the velocity range is from 2.0 to 2.5 .

The formulation implemented for the matrix of this model (3) was the same as it was done with model of (2).

TABLE III

OPTIMIZATION PARAMETERS FOR EQ. (3) MODEL

\begin{tabular}{|c|c|c|c|}
\hline \multirow[b]{2}{*}{$\begin{array}{c}\text { Simulation } \\
\text { data equation } \\
\text { M-2 }\end{array}$} & \multicolumn{3}{|c|}{ Parameters } \\
\hline & $\begin{array}{l}\text { Impact } \\
\text { velocity }\end{array}$ & $\begin{array}{c}\text { Impact } \\
\text { angle / } K\end{array}$ & $\begin{array}{c}\text { Erosion } \\
\text { Lab } \\
\text { experimental } \\
\text { simulated values }\end{array}$ \\
\hline OPTIMIZATION 1 & $40 \mathrm{~m} / \mathrm{s}$ & variables & 3 \\
\hline OPTIMIZATION 2 & $80 \mathrm{~m} / \mathrm{s}$ & variables & 18 \\
\hline
\end{tabular}

Note: This optimization is more complicated as it involves two variables, and one of them is a sine, a trigonometric function.

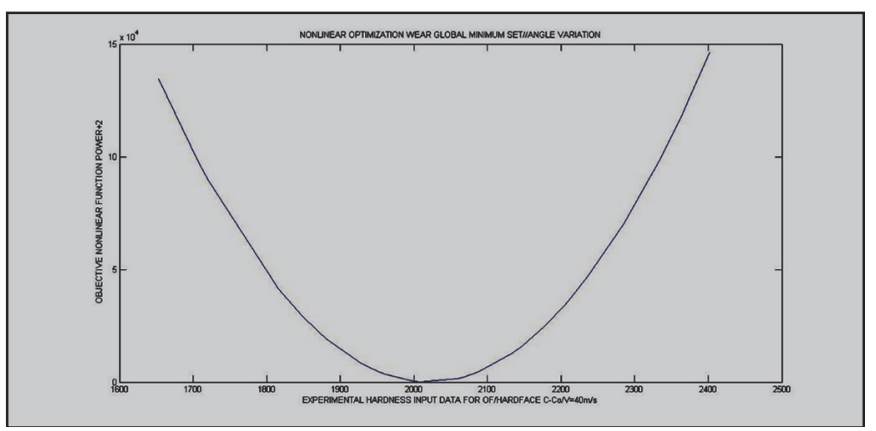

Fig. 8. Objective function (OF) nonlinear optimization results for Table VI and Eq. (3) model, Matlab 2009-12. The impact velocity is $40 \mathrm{~m} / \mathrm{s}$. Results are acceptable with a Global Minimum sharply determined and running time is lower than a second.

TABLE IV

NuMERICAL DATA OBTAINED From NONLINEAR OPTIMIZATION OF EQ. (3)

\begin{tabular}{|c|c|c|}
\hline Search point & $\begin{array}{c}\text { Optimal } K / \text { hardness } \\
\text { impact angle value } \\
\text { (inverse method) } \\
v_{\text {particles }}=40 \mathrm{~m} / \mathrm{s}\end{array}$ & $\begin{array}{c}\text { Residual of objective } \\
\text { function (OF) }\end{array}$ \\
\hline$x=[1.0 ; 0.5]$ & $0.0343 / 74.2107^{\circ}$ & $1.4155 \cdot 10^{3}$ \\
\hline$x=[0.8 ; 0.2]$ & $1.0473 / 86.0262^{\circ}$ & $1.8135 \cdot 10^{3}$ \\
\hline$x=[0.5 ; 0.9]$ & $0.0952 / 79.5778^{\circ}$ & $1.4135 \cdot 10^{3}$ \\
\hline$x=[0.5 ; 0.8]$ & $0.9029 / 85.7850^{\circ}$ & $1.6135 \cdot 10^{3}$ \\
\hline Comments & $\begin{array}{c}\text { Acceptable but variable result for optimization of two } \\
\text { variables, low residual of OF global minimum exact } \\
\text { for any search point, angle of sine has influence }\end{array}$ \\
\hline
\end{tabular}

Note: Experimental values, impact velocity, material density, and all parameters implemented are from laboratory measurements results. However, here the sine angle makes variations according to the search point.

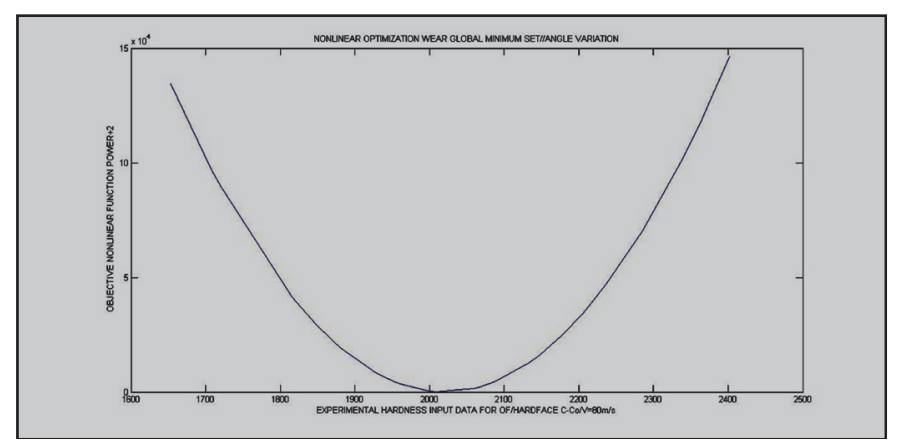

Fig. 9. Objective function (OF) nonlinear optimization results for Table 7 and Eq. (3) model, Matlab 2009-12. The impact velocity is $80 \mathrm{~m} / \mathrm{s}$. Results are acceptable with a Global Minimum sharply determined and running time is lower than a second.

TABLE V

NuMERICAL DATA OBTAINED From NONLINEAR OPTIMIZATION OF EQ. (3)

\begin{tabular}{|c|c|c|}
\hline Search point & $\begin{array}{c}\text { Optimal } K / \text { angle } \\
\text { value } \\
\text { (inverse method) } \\
v_{\text {particles }}=80 \mathrm{~m} / \mathrm{s}\end{array}$ & $\begin{array}{c}\text { Residual of objective function } \\
(\mathrm{OF})\end{array}$ \\
\hline$x=[0.8 ; 0.9]$ & $0.0015 / 74.4507^{\circ}$ & $1.4235 \cdot 10^{3}$ \\
\hline$x=[0.85 ; 0.9]$ & $1.0439 / 85.9286^{\circ}$ & $1.5135 \cdot 10^{3}$ \\
\hline$x=[0.4 ; 0.9]$ & $1.9295 / 86.8127^{\circ}$ & $1.4135 \cdot 10^{3}$ \\
\hline Comments & $\begin{array}{c}\text { Acceptable result for optimization of low residual of OF } \\
\text { global minimum exact for any search point, sine angle } \\
\text { and search point show that OF is not totally convex, it is } \\
\text { a product of variables in OF }\end{array}$ \\
\hline
\end{tabular}

Note: Particle velocity is $v=80 \mathrm{~m} / \mathrm{s}$. Experimental values, impact velocity, material density, and all parameters implemented are from laboratory measurements results. 


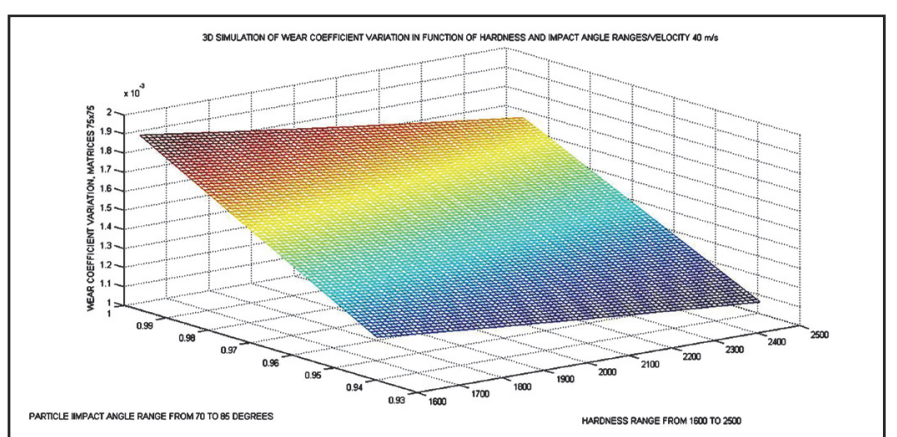

Fig. 10. 3D surfactal simulation results for Table V and Eq. (3) model. The impact velocity is $40 \mathrm{~m} / \mathrm{s}$. Range of angles for Eq. 3 is $\left[70^{\circ} ; 85^{\circ}\right]$. Range of hardness is $[1600 ; 2500]$. Results corroborate the Tables VI, VII numbers. Thus, a global minimum is not totally well-defined. Matrices of imaging are $75 \times 75$.

According to simulations and optimization results shown, the practical conclusion is that not all objective functions are well-defined in convexity. The graphical 3D optimization, [7] is a good tool to find coherent values for variables when their number increases - especially when there is a product of consecutive variables. Along a series of contributions, the basis of graphical optimization were presented with initial algorithms, [38]-[44]. For example, in [43], [44], scanned cloud data (about $10^{6} 3 \mathrm{D}$ points) from specimen-surfaces were fitted to a geometrical hyperboloid shape with nonlinear least squares software. In the subsequent section, models with continuous functions are overviewed.

\section{L 1 NORM GRAPHICAL OPTIMIZATION DEMONSTRATION AND METHOD}

The present section deals with the setting of an objective function in $\mathrm{L}_{1}$ Norm for Graphical Optimization images. The selected model [4], [7] is the Meguturk model (1979). This model optimization was presented in previous publications because of its facilities for illustrations and examples for a general method.

The model shows that erosion is largely a function of particle impact velocity and angle. It is important to remark that the model is totally applicable to any power plant mathematical model. The cursor of the software can give the numerical desired values for lab or experimental of any type. The model for small and large particle impact angles is given as an easy tool to carry out graphical optimization, as follows:

$$
E=v^{2.5}\left[\left(1.63 \mathrm{e}-6(\cos \alpha)^{2.5}\right)+\left(4.68 \mathrm{e}-7(\sin \alpha)^{2.5}\right)\right] .
$$

This is the simplest equation valid for particle impact angles $\geq 22.7^{\circ}$. For angles $<22.7^{\circ}$, the model formulation reads:

$$
E=v^{2.5}\left[\left(1.63 \mathrm{e}-6(\cos \alpha)^{2.5} \sin \left(\frac{180}{45.4} \alpha\right)\right)+\left(4.68 \mathrm{e}-7(\sin \alpha)^{2.5}\right)\right],
$$

where $E$ is the erosion rate in $\left(\mathrm{mm}^{3} \mathrm{~g}^{-1}\right)$, and impact velocity and angle $\alpha$, measured in $\left(\mathrm{m} \mathrm{s}^{-1}\right)$ and radians, respectively. The volumetric erosion rate $\left(\mathrm{mm}^{3} \mathrm{~g}^{-1}\right)$, i.e., 2 variables. This simple equation illustrates the following series of computational simulations because the implementation of programming matrix algebra-operations is fast, although the application of the matrix-algebra concepts in programming requires special calculations to obtain accurate results.
Therefore, the algorithm setting the Chevyshev $L_{1}$ optimization reads:

$$
\begin{aligned}
& \text { minimize, } \\
& F(\vec{x})=\sum_{i=1}^{i=N}|U-f(\vec{x})| ; \\
& \text { without constraints } \\
& \text { where } U \text { is the value } \\
& \text { of optimal magnitude } \\
& \text { of erosion and } \\
& f(\vec{x}) \text { is Megaturk model. }
\end{aligned}
$$

This Chevyshev objective function [40]-[42], [45] in a step forward related to previous publications, will be set in the computational programming at $z$ axis. Therefore, the information at surfactal graphics is for the objective function magnitude. In such a way, the determination of the global values can be taken directly without any numerical optimization subroutine.

In Figs. 11 and 12, the results of the program are shown and the graphical optimization is sharply presented. In Table VI, all the numerical data for this graphical optimization are detailed. The difference is the setting of objective function at $z$ axis. Appendix I.I substantiates the importance of the demonstration of the Graphical Optimization Method for an objective function.

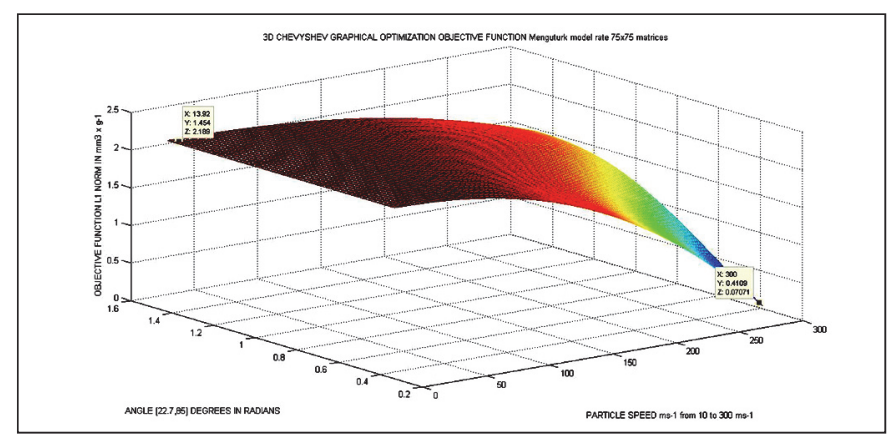

Fig 11. Chevyshev Graphical Optimization with Objective function at $z$ axis. Exact Global minimum was reached at erosion optimal values of speed and impact angle. The searched erosion value is approximately $2.18 \mathrm{~mm}^{3} / \mathrm{kg}$. Data cursor shows global minimum and global maximum.

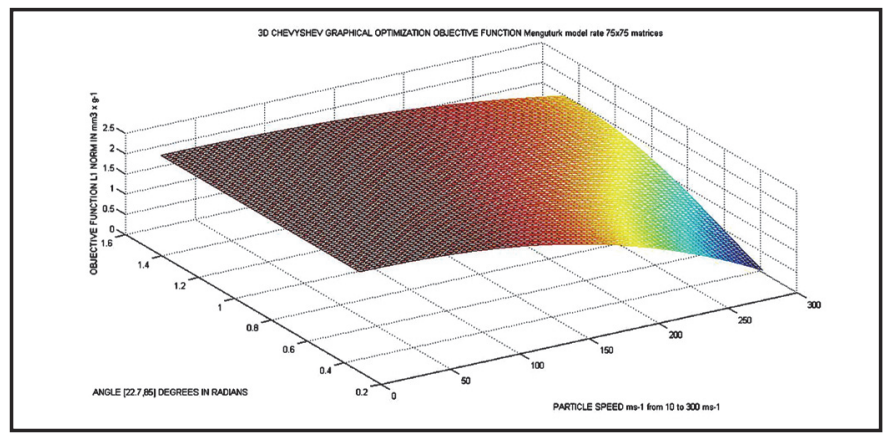

Fig. 12. Chevyshev Graphical Optimization with Objective function at $z$ axis. Exact Global minimum was reached at erosion optimal values of speed and impact angle. The searched erosion value is $2.18 \mathrm{~mm}^{3} / \mathrm{kg}$. Data cursor shows global minimum and global maximum.

In these figures provided above, the search for global minimum is obtained sharply and it is possible to assert that the usage of Graphical Optimization Method [Casesnoves, 
2016-7] has been computationally proven. Further developments with other types of objective functions can be reached provided the software is improved for specific model equations.

TABLE VI

GRAPHICAL OPTIMIZATION EXACT RESULTS FOR OBJECTIVE FUNCTION

\begin{tabular}{|c|c|c|c|}
\hline \multirow{2}{*}{$\begin{array}{c}\text { 3D graphical } \\
\text { optimization image } \\
L_{1} \text { norm }\end{array}$} & $\begin{array}{c}\text { Impact } \\
\text { velocity }\end{array}$ & $\begin{array}{c}\text { Impact } \\
\text { Angle radians }\end{array}$ & $\begin{array}{c}\text { Erosion } \\
\text { resulting value } \\
\left(2.18 \mathrm{~mm}^{3} / \mathrm{kg}\right. \\
\text { Selected })\end{array}$ \\
\cline { 2 - 4 } Global Maximum & $13.92 \mathrm{~m} / \mathrm{s}$ & 1.454 & 2.189 \\
\hline Global Minimum & $300 \mathrm{~m} / \mathrm{s}$ & 0.4109 & $\begin{array}{c}0.07071 \\
\text { almost exact }\end{array}$ \\
\hline $\begin{array}{c}\text { 3D Intervals of } \\
\text { parameters }\end{array}$ & {$[10 ; 300]$} & $\begin{array}{c}{[22.7 ; 85]} \\
\text { in degrees }\end{array}$ & {$[0.2 ; 18]$} \\
\hline Comments & $\begin{array}{c}\text { This is an important group of results as it involves a } \\
\text { sharp proof of the instant localization of a } \\
\text { Global Maxima/Minima for a model into an } \\
\text { Objective Function, in this case } L_{1} \text { norm; all that is } \\
\text { visualised in 2 previous graphics }\end{array}$ \\
\hline
\end{tabular}

In Appendix I.II it is presented a complementary example of graphical Optimization method to select a ROI, *regoon of interest) with constraints for laboratory conditions or manufacturing requirements.

\section{THE SECONd GENERATION OF TRIBOLOGY MATHEMATICAL MODELS, NEW ASPECTS IN MODERN TRIBOLOGY}

After the recent decades of significant development of number and varieties of tribology models, e.g., wear, erosion, corrosion, tribocorrosion, abrasion etc. [46], the current investigation of engineering manufactured materials has resulted in non-singular compound materials production - for example, reinforced hardfacing metal composites of alloy type. This, specifically in power engineering plants, is the consequence of new requirements for multi-functional materials in the industry, plant design/construction, and the emerging large number of a variety of options in every branch of any industry. For instance, from the automobile to energy plant pipes, it is possible to find a considerable choice of different types for each particular necessity.

Therefore, since requirements of hardness, plastic deformation with/without fatigue magnitudes, cutting erosion, or brittle resistance involve a large number of situations, the search for mixed materials, e.g., carbides, composites, kind of reinforcements, or similar compounds, has experienced the significant development of industrial compounds - with the additional effect of multi-varied manufacturing options and industrial expansion.

To date, the classical mathematical models in tribology based on discrete or single-valued parameters can be considered rather obsolete, since new materials are compounded by several phases of different chemical and physical conditions, [2], [5], [19]. This fact implies that the surface exposed to abrasion wear damage for particles, for instance, is not homogenous in wear resistance because the fluence of abrasive particle impact is probabilistically distributed over the non-equal spatial compounded material surface - and just the same concept is applied to corrosion, biotribology, or tribocorrosion. Fig. 13 provides a basic sketch with flow chart for the industrial modelling manufacturing classical method in reinforced hardfaces. The method usually is to collect laboratory tribotesting data, and implement the database in the selected model. The last step is optimize the model parameters for that type of material and physical constraints.

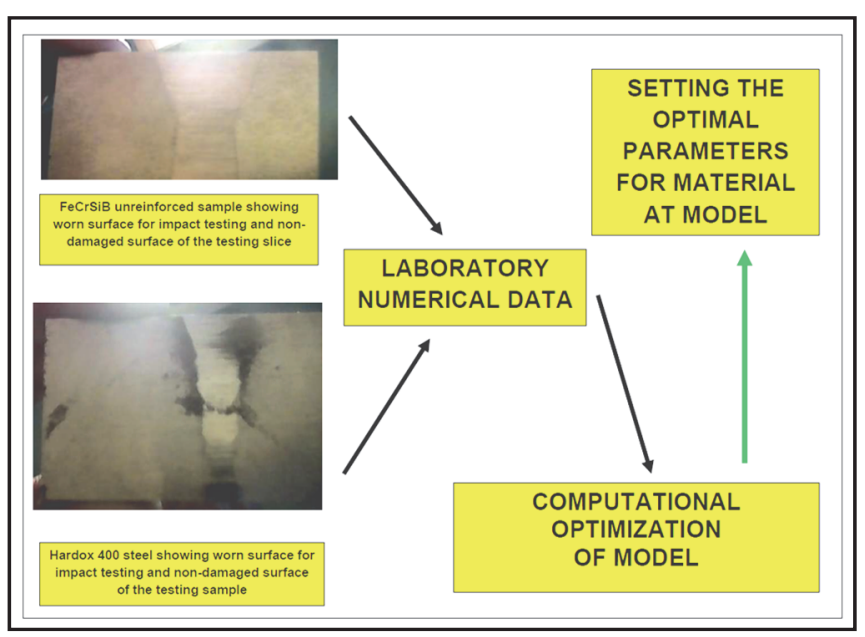

Fig. 13. Method for modelling development. From experimental lab data the cloud of numerical values is set within the model for computational optimization.

However, discrete modelling continues being useful at least as a first approximation. Combined discrete models with Weibull distribution that can be improved in future may be considered a primary stage to pass onto more perfection models. In Fig. 14, a stratified model of Kulu, Casesnoves and Surzhenkov is presented. This model is based on Gotzmann and Beckmann classical equations.

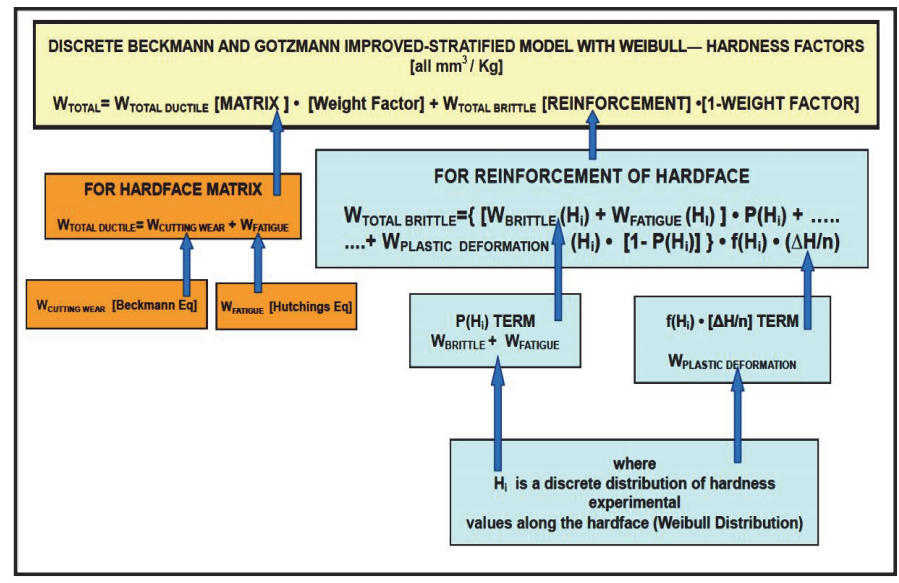

Fig. 14. Mathematical construction of a stratified discrete model based on successive applications of Beckmann and Gotzmann Equations [ Casesnoves, Kulu, Suzhenkov, 2016-7].

It is assumed that the parameters of the models should become at least differentiable and integrable functions for every type of compound material, in spatial surface and thickness, rather than a series of discrete numerical values or an average approximated value for the surface. 
The new generation of tribology mathematical models conceived to obtain improved/precise determination of tribology engineering values should be formed by continuous functions of parameters, derivable and integrable for the material mathematical and numerical range conditions [1]-[6], [21], [45].

As a result, a number of nonlinear optimization, stochastic optimization, statistical and probabilistic variables have concentrated their effect on the design of new generation of tribology models for future high-precision applications [1][6], [21], [45].

An important complementary subject in this type of materials production is the group of constraints to be taken into account for improvements in circular economy. This, in particular under the European Union conditions, constitutes a key point for a sustainable environmental and industrial development.

Therefore, it is necessary to take new measures towards the subsequent generation of tribology models for future extensive applications.

\section{Markov Chain Modelling For Metal Hardfaces: A BRIEF INTRODUCTION}

The section focuses on some aspects of Markov Chain Method for optimization of hardfaces when the matrix, binding zone and reinforcement are at the meso and macro level of magnitude size.

Figure 15 illustrates how this stochastic method could be applied in a fluence of impact particles whose kinetic energy is almost constant. The surfactal impact probabilities determined by Monte-Carlo method are fundamental. One particle could impact matrix, binding zone, or reinforcement depending of the probability of each zone.

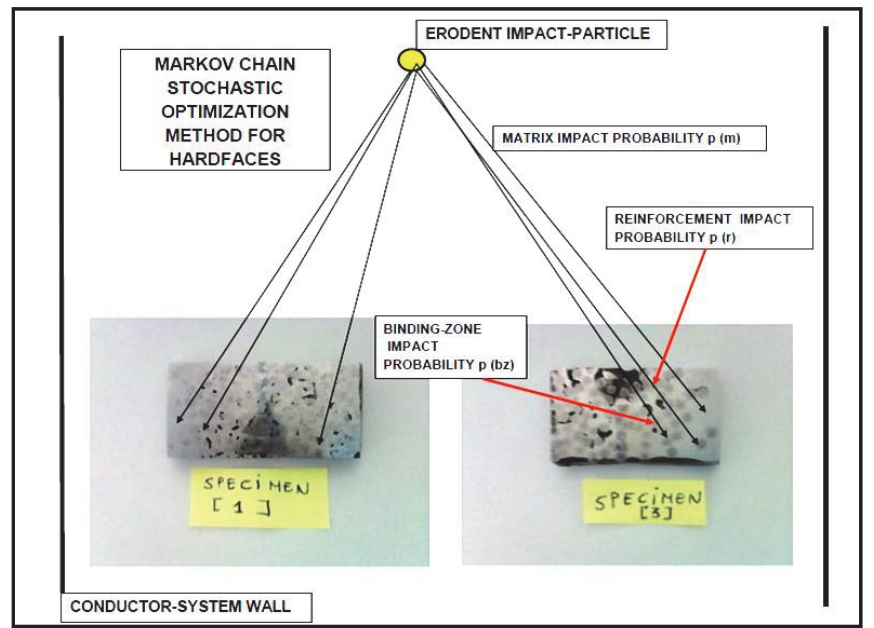

Fig. 15. Setting the impact probability for WC-Co hardfaces. Namely, matrix, $p(m)$, reinforcement, $p(r)$, and binding zone, $p\left(b_{z}\right)$. On the right, spherical hardface manufactured, and on the left, polygonal reinforcement hardface with recycled metal.
Figure 15 demonstrates Markov Chain optimization technique with two different hardface laboratory specimens. On the right - manufactured with spherical reinforcement, and on the left - the same chemical composition with polyedrical reinforcement instead - recycled metal, in other words.

Figure 15 shows the basic phenomena of impact erosion wear that happens in one of the most difficult bifurcations of pipes, namely, the ' $T$ ' shaped bifurcation, that is, $\underline{\underline{L}}$, so the impact of particles is usually in an approximate range of $[-30$; 30] degrees and this method constitutes the simplification of the fluid dynamics technique. The integral-differential model is applicable in this situation. In future contributions, this topic for impact wear will be extensively developed.

\section{CONCEPT AND FUNDAMENTALS OF INTEGRAL- DIFFERENTIAL MODELLING}

In other studies [4], the T1 Integral-differential model in tribology was presented. The basic concept of this model is the improvement at the upper threshold level from finite-discrete determination in classical models towards infinitesimal calculus within a model equation. In other words, conventional models usually show the limitations related to mathematical operativity of simple calculations and statistics, e.g., determination coefficient for a series of cloud data, standard deviation, discrete graphics made with splines, etc.

However, integral-differential models are subject of infinitesimal operations, such as derivatives, directional derivatives, integration, etc. - namely, the second generation of models. For example, in most cases the erosion obtained constitutes a Fredholm integral equation of first kind in the integral-differential model.

Furthermore, it could be hypothesized that any discrete model may be transformed to the integral-differential model, provided that at least one parameter changes to a function based on laboratory data. In the literature, it is not frequent to find models with mathematical functions, explicit or implicit for a secondary linked equation. The generalization of the integral-differential model is related to something whose parameters can be converted to functions previously determined by trustworthy extensive lab database. In the subsequent section, the simulation of a simple model whose particle velocity at the curved zone of a pipe is a function of time during the stream of sand impact particles is introduced.

\section{FORMAL SIMULATION OF INTEGRAL-DIFFERENTIAL MODELLING}

Figure 16 provides a simple sketch of an elbow in a mechanical system of power plant. In simulation, it is supposed that there is a stream or erodent particles during a time interval. The stream time function of velocity of particles could be roughly approximated to a Gaussian, since at first velocity increases, reaching a maximum value, and then decreases together with the cease of the stream at the mechanical system of the power plant. 


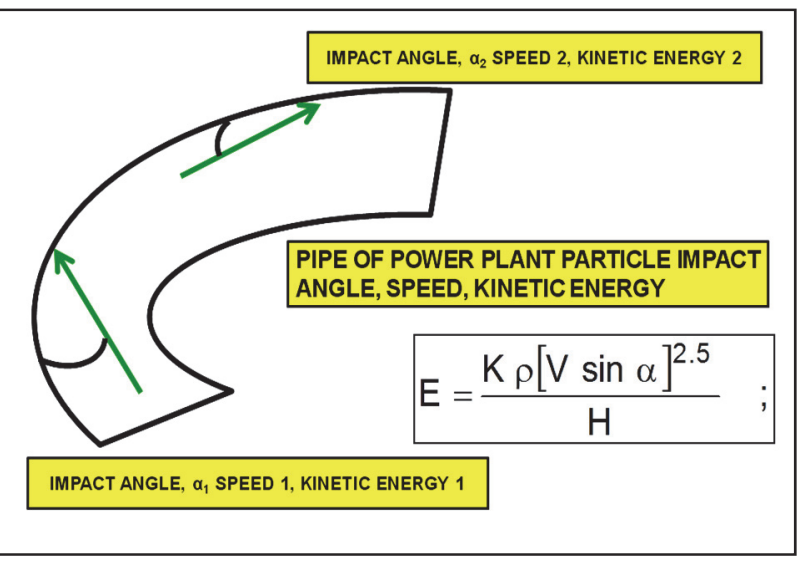

Fig. 16. Concept of usage of a mathematical model in a pipe during a stream of erodent particles. The impact particle, kinetic energy, speed, and impact angle variations along curved pipe regions determine constraints for modelling. The formula that is set in the sketch corresponds to Eq. 4 .

Therefore, using the simplified equation, as in the previous sections without power of speed:

$U=\frac{K \rho v}{H}$.

It can be transformed to:

$U=\frac{K \rho v(t)}{H}$.

And the velocity function approximated as:

$$
v(t)=\lambda \mathrm{e}^{-\theta\left[t-t_{\mathrm{m}}\right]^{2}},
$$

where $\theta$ is a constant depending on characteristics of mechanical system streams, $\lambda$ is a constant for a Gaussian, and other additional constants in a Gaussian are suppressed for the sake of simplicity. In this simple Hutchings model, $U$ is defined as erosion per second, i.e., a rate of erosion for a defined velocity. If a velocity function $v(t)$ is set, $U$ becomes an erosion rate for a defined velocity function at time $t$. Here is used this approximation to simplify the algorithm that will be extensively developed in next contributions. Approximations for this model-algorithm are to consider a stream of particles whose speed magnitude follows a Gaussian curve along the stream time interval. That is, the velocity of the particles commences at low magnitude values, then reaches a peak (the Gaussian maximum), and after that falls to zero when the stream is over. The notation $t$ is time, and $t_{\mathrm{m}}$ is the time at the maximum velocity of particles in the stream.

Therefore,

$$
U(t)=\frac{K \rho}{H} \lambda \mathrm{e}^{-\theta\left[t-t_{m}\right]^{2}}
$$

What is intended to show for the integral-differential model is its utility for accumulative erosion rate when the velocity function changes during a time interval. However, to simplify even more, it is useful to centre the Gaussian at origin and consider interval of stream $[-t ; t]$. Thus, erosion per second at $v(t)$ :

$$
U(t)=\frac{K \rho}{H} \lambda \mathrm{e}^{-\theta t^{2}}
$$

Direct application of chain-theorem-derivation, $\frac{\mathrm{d} U}{\mathrm{~d} t}=\frac{\mathrm{d} U}{\mathrm{~d} v} \cdot \frac{\mathrm{d} v}{\mathrm{~d} t}=$$$
=\left(\frac{K \rho}{H}\right) \cdot\left(\frac{\mathrm{d} v(t)}{\mathrm{d} t}\right) \text {. }
$$

Thus,

$$
\begin{aligned}
& \text { integrating along the stream } \\
& \text { time interval }[0 ; t] \\
& \int_{0}^{t} \mathrm{~d} U=\int_{0}^{t}\left(\frac{K \rho}{H}\right) \cdot\left(\frac{\mathrm{d} v(t)}{\mathrm{d} t}\right) \mathrm{d} t=t \\
& =\text { Integral Equation of First Kind, } \\
& =\left(\frac{K \rho}{H}\right) \int_{0}^{t}-2 t \theta \mathrm{e}^{-t^{2}} \mathrm{~d} t=\ldots
\end{aligned}
$$

Further determination of this equation is as follows:

$$
\begin{aligned}
& {[U]_{0}^{t}=\left(\frac{K \rho}{H}\right) \lambda \int_{0}^{t}-2 t \theta \mathrm{e}^{-t^{2}} \mathrm{~d} t=} \\
& =\left(\frac{K \rho}{H}\right) \cdot\left[\lambda\left(1-\mathrm{e}^{-\theta t^{2}}\right)\right] . \\
& \text { which is useful } \\
& \text { simplification; }
\end{aligned}
$$

[Algorithm 2, Casesnoves 2017]

This is the total cumulative erosion rate at curved zone during the interval $[0, t]$ of particle variation of velocity during a stream within the pipe. More precise algorithms will be specified in next contributions. It should be noted that this basic approach is usually done with fluid dynamics models that usually are more complicated, although effective [22], [23], [27], [28], [35].

If the purpose is to determine the cumulative erosion magnitude during an interval of time, the integral equation is different. It is necessary to integrate the Eq. 8 along a time interval without taking derivatives [37], [47]. That is, the area of the function of Eq. 8, between the curve and $x$ axis, for a time interval defined at the $\mathrm{x}$ axis, corresponds to the cumulative erosion for a Gaussian stream of particles with velocity $v$ during that time interval. Note the mathematical difference between the cumulative erosion rate and the cumulative erosion magnitude, both of them during a time interval. In Eq. (8), $U(t)$ is erosion rate, usually at TUT per hour or half hour depending on the time of the experiment. In Fig. 17, it is shown the visual demonstration of the error that occurs in erosion magnitude during a time interval when it is taken velocity as constant, compared to a Gaussian curve. 


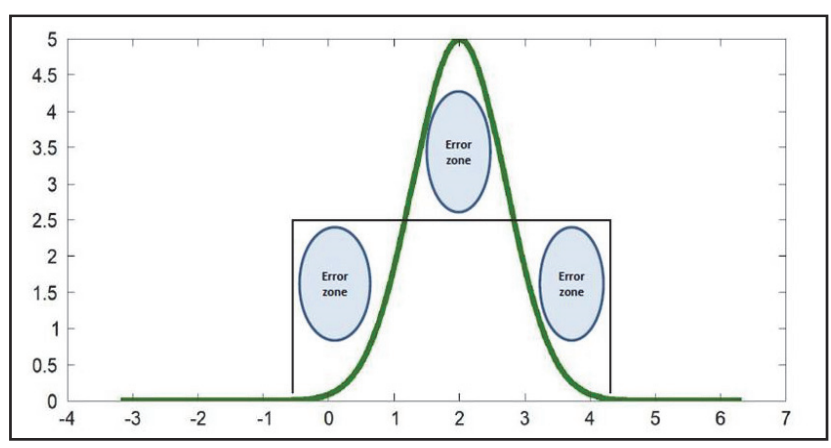

Fig. 17. Sketch of the error that occurs when constant velocity during a stream of particles happens, compared to a more real velocity distribution in function of time (Gaussian). In $x$ axis time and in $y$ axis erosion. Values are not significative, it is a conceptual-graphical example. This graphical demonstration is related to cumulative erosion.

This simulation highlights the mathematical significance of the integral-differential model method. The model selected is a basic impact erosion of Hutchings equation [17]. The algorithm is set simple with velocity function, and can be extended towards more complicated equations using partial differential equations, total differentials, integral-differential equations, and numerical approximations.

\section{DISCUSSION AND CONCLUSION}

The present paper supposes a continuation of the study initiated in the previous article of inverse methods and graphical computational optimization in tribological erosion models. However, this study focused on nonlinear optimization algorithms, integral-differential model proofs, direct applications of inverse problem theory, Markov Chain, and second generation of tribology model mathematical analysis. The models that were presented for optimization were detailed to demonstrate the method of inverse nonlinear optimization with specific software. All the selected models in this study are appropriate to be implemented in any other more complicated equation, no matter the number of variables to be optimized - large-scale multiobjective optimization could be carried out with the programming designed properly. In particular, graphical 3D simulation surfaces were shown for sharp learning of this new technique.

The most important improvements are related to the formal demonstration of integral-differential Model with specific algorithms. The graphical optimization was proven for Meguturk model, [7], and the development of simulation of integral-differential model in previous equations. It is considered that this mathematical and computational proof is a formal step towards large applications of this specific technique both in T1 and T2 models. 3D graphical optimization method, with this demonstration, is formally set as a nonlinear optimization technique in mathematical modelling.

At present, it is assumed that, in order to obtain more precise results of modelling [48], future models should consider more parameters in optimization process. These include, e.g., modulus of elasticity and fracture toughness. On the other hand, the role of microstructure influencing factors, such as wetting of reinforcement by molten matrix or residual stress distribution also contributes to modelling advances.
All results are considered accurate and acceptable, conditioned to serial lab experimental validation in future research. The practical applications in erosion/corrosion models for power plants, energy industry, and circular production follow the proven method with adequate software. It should be noted that the actual environmental engineering advances in recycling industry [49] from an additional factor to support the tribology-biotribology, corrosion and tribocorrosion research in computational and materials engineering.

\section{ACKNOWLEDGEMENTS AND SCIENTIFIC ETHICS STANDARDS}

TUT is gratefully acknowledged for all the facilities for research. This study was carried out, and their contents are done according to the European Union Technology and Science Ethics. Reference, 'European Textbook on Ethics in Research'. European Commission, Directorate-General for Research. Unit L3. Governance and Ethics. European Research Area. Science and Society. EUR 24452 EN. The research was conducted by the authors, the software, calculations, images, mathematical propositions and statements, reference citations, and text is original for the author. The article also contains unique numerical data and special improved images together with algorithms. The introduction is the basis of the previous paper to understand mathematics and optimization of the present contribution. When something is taken from a source, it is adequately recognized. Ideas from previous publications were emphasized with an aim of clarification [48], [50].

\section{REFERENCES}

[1] M. S. ElTobgy and M. A. Elbestawi, "Finite Element Modeling of Erosive Wear," International Journal of Machine Tools and Manufacture, vol. 45, no. 11, pp. 1337-1346, Sep. 2005.

https://doi.org/10.1016/j.ijmachtools.2005.01.007

[2] F. Casesnoves, M. Antonov, and P. Kulu, "Mathematical Models for Erosion and Corrosion in Power Plants. A Review of Applicable Modelling Optimization Techniques," in 2016 57th International Scientific Conference on Power and Electrical Engineering of Riga Technical University (RTUCON), Oct. 2016.

https://doi.org/10.1109/rtucon.2016.7763117 ISBN 978-1-5090-3732-2. USB ISBN 978-1-5090-3730-8. ISBN 978-1-5090-3722-2.

[3] J. Y. Shin, Y. J. Jeon, D. J. Maeng, J. S. Kim, and S. T. Ro, "Analysis of the Dynamic Characteristics of a Combined-Cycle Power Plant," Energy, vol. 2, pp. 1085-1098, Dec. 2002. https://doi.org/10.1016/s0360-5442(02)00087-7.

[4] F. Casesnoves and A. Surzhenkov, "Mathematical Models in Mechanical and Biomedical Tribology With Computational Simulations/Optimization Methods," International Journal of Scientific Research in Computer Science, Engineering and Information Technology, vol. 2, issue 1, 2017. ISSN 2456-3307.

[5] F. Casesnoves, "Erosion Wear Mathematical Model for WC-Co Reinforcement Hardness Distribution in Fe-Based Alloy Matrix With Evoluted Algorithms," International Journal of Scientific Research in Science, Engineering and Technology, vol. 3, issue 5, pp. 336-344, 2017. Print ISSN 2395-1990. Online ISSN 2394-4099.

[6] F. Casesnoves, "2D Computational-Numerical Hardness Comparison Between Fe-Based Hardfaces With WC-Co Reinforcements for IntegralDifferential Modelling," in Proc. Materials Science and Applied Chemistry 58th International Conference, 2017, Trans Tech Publications, Switzerland.

[7] F. Casesnoves and A. Surzhenkov, "Inverse Methods for Computational Simulations and Optimization of Erosion Models in Power Plants: A Numerical-Sufactal Nonlinear Optimization of Modelling," in Proc. 2017 IEEE 58th International Scientific Conference on Power and Electrical Engineering of Riga Technical University (RTUCON), Oct. 2017, paper 139. https://doi.org/10.1109/rtucon.2017.8125630 
[8] F. Casesnoves, "2D Computational-Numerical Hardness Comparison Between Fe-Based Hardfaces With WC-Co Reinforcements for IntegralDifferential Modelling," Key Engineering Materials, vol. 762, pp 330338, Feb. 2018. https://doi.org/10.4028/www.scientific.net/kem.762.330

[9] L. Crocker, A Review of Current Methods for Modeling Erosive Wear. NPL Report, 2011.

[10] M. Abramowitz and I. Stegun, Handbook of Mathematical Functions. Applied Mathematics Series, 55, 1972.

[11] F. Casesnoves, "A Monte-Carlo Optimization Method in Numerical Reuleaux Method for the Movement Analysis of Pseudo-Rigid Bodies,' in Proc. 10th SIAM Conference in Geometric Design and Computing joint to Approximation Theory Conference, Texas, San Antonio, USA, 2007, pp. 4-5.

[12] G. Luenberger, Linear and Nonlinear Programming, 4th ed. Springer, 2008.

[13] A. Ots, Oil Shale Combustion. Tallinn, Estonia: TUT Press, 2004.

[14] K. Holmberg and A. Erdemir, "Influence of Tribology on Global Energy Consumption, Costs, and Emissions," Friction, vol. 5, issue 3, pp. 263-284, Sept. 2017.

[15] F. Casesnoves, "3D Improved Mathematical Model for Lumbar Intervertebral Ligaments (LILs)," in Proc. SIAM Life Sciences Conference joint to SIAM Annual Conference San Diego, 2012, pp. 25-27.

[16] B. G. Mellor, Surface Coatings for Protection Against Wear. CRC Press. Woodhead Publishing in Materials, 2006.

[17] I. Hutchings, "A Model for the Erosion of Metals With Spherical Particles at Normal Incidence," Wear, vol. 70, issue 3, pp. 269-281, Aug. 1981. https://doi.org/10.1016/0043-1648(81)90347-1

[18] G. Sheldon, I. Finnie, "The Mechanism of Material Removal in the Erosive Cutting of Brittle Materials," J. Eng. Ind., vol. 88, issue 4, pp. 393-400. https://doi.org/10.1115/1.3672667

[19] I. Kleis and P. Kulu, Solid Particle Erosion. Springer. 2008. https://doi.org/10.1007/978-1-84800-029-2

[20] F. Casesnoves, "An Optimization Method for Static Wedge-Radiation Filters in Radiation Therapy," Master Thesis in Physics, Eastern Finland University, 2001.

[21] K. Balamanikandasuthan, K. Arun, and S. Palam, "Design and Fabrication of Erosion Protection Shield for Boiler Tubes and Its Analysis," International Journal of Mechanical and Materials Engineering, vol. 1, issue 1, pp. 39-52, 2015.

[22] D. Bertsekas, Nonlinear Programming, 2nd ed. Athena Scientific, 2003.

[23] J. Borwein, Convex Analysis and Nonlinear Optimization, 2nd ed. CMS Books in Mathematics. Springer, 2000.

[24] F. Casesnoves, "Large-Scale Multiobjective Matlab Optimization Toolbox (mot) Computing Methods in Radiotherapy Inverse Treatment Planning," in High Performance Computing Conference, 2007, Nottingham University.

[25] F. Casesnoves, "Geometrical/Computational Dynamics Approximations for Helicopter-Rotor Instantaneous Rotation Center in Turbulence With Numerical Reuleaux Method," International Journal of Engineering and Innovative Technology, vol. 4, issue 3, pp. 175-184, 2014.

[26] F. Casesnoves, "Geometrical Algorithms for Civil Helicopter $(\mathrm{CH}$ Rotor Blades Instantaneous Rotation Center (IRC) Determination in Deformable/Turbulence Conditions Using the Numerical Reuleaux Method (NRM): A Nonlinear Optimization Method in Aerospace Engineering Dynamics," in Proc. SIAM Conference on Applied Algebraic Geometry Fort Collins. 2013, pp. 112-114.

[27] F. Hildebrand, Introduction to Numerical Analysis, 2nd ed. Dover Publications, Inc., 1987.

[28] L. Fausett, Applied Numerical Analysis Using Matlab. Pearson International, 2008.

[29] S. Kajda, S. Harvey, and E. Wilusz Eds., Encyclopedia of Tribology. Elsevier, 1990.

[30] H. Liao, B. Normand, and C. Coddet, "Influence of Coating Microstructure on the Abrasive Wear Resistance of WC/Co Cermet Coatings," Surface and Coatings Technology, vol. 124, issue 2-3, pp. 235-242, 2000. https://doi.org/10.1016/s0257-8972(99)00653-2

[31] S. Basu, Freemat v4.0 Documentation. 2009.

[32] S. Basu, Freemat v4.2 Documentation. 2012.

[33] C. Moler, Numerical Computing With Matlab. SIAM, 2004. https://doi.org/10.1137/1.9780898717952

[34] S. Gherpade, Introduction to Algebraic Geometry. Department of Mathematics Publications. Indian Institute of Technology Bombay, 2014.
[35] W. Cheney and W. Light, A Course in Approximation Theory: Graduate Studies in Mathematics. Am. Math. Soc., vol. 101, 2000.

[36] A. Crowell and J. Slesnicks, Calculus With Analytic Geometry. Version 3.03. GNU Free Documentation License. Free Software Foundation. 2008.

[37] W. Strauss, Partial Differential Equations, 2nd ed. Wiley, 2008.

[38] Q. Chen, D. Li, "Computer Simulation of Solid-Particle Erosion of Composite Materials," Wear, vol. 255, issue 1-6, pp. 78-84, Aug.-Sept. 2003. https://doi.org/10.1016/s0043-1648(03)00065-6

[39] F. Casesnoves, "Experimental Simulations of the Numerical Reuleaux Method (NRM) for Lumbar Artificial Disk Implants IRC Determination," in Proc. SIAM Conference in Computational Science and Engineering, 2009, PP1 Section, pp. 1-2.

[40] F. Casesnoves, "Theory and Primary Computational Simulations of the Numerical Reuleaux Method (NRM)," International Journal of Mathematics and Computation, vol. 13, no. D11, pp. 90-110, 2011.

[41] F. Casesnoves, "Applied Inverse Methods for Deformable Solid Dynamics/Kinematics in Numerical Reuleaux Method (NRM)," International Journal of Numerical Methods and Applications, vol. 9, no. 2, pp. 109-131, 2013.

[42] F. Casesnoves, "Applied Inverse Methods for Optimal GeometricalMechanical Deformation of Lumbar Artificial Disks/Implants With Numerical Reuleaux Method. 2D Comparative Simulations and Formulation," Ethan Publishing Computer Science Applications, vol. 2, no. 4, pp. 1-10, 2015.

[43] Casesnoves, F. "Computational simulations of vertebral body for optimal instrumentation design," Journal of Medical Devices, vol. 6, issue 2, pp. 14-25, 2012. https://doi.org/10.1115/1.4006670

[44] F. Casesnoves, "Computational Simulations of Anterior Vertebral Body for Optimal Surgical Instrumentation Design," Journal of Medical Devices, vol. 4, issue 2, pp. 25-26, 2010.

[45] V. Camomilla and A. Cereatti, "An Optimized Protocol for Hip Joint Centre Determination Using the Functional Method," Journal of Biomechanics, vol. 39, issue 6, pp. 1096-1106, 2006. https://doi.org/10.1016/i.jbiomech.2005.02.008

[46] L. Li and D. Li, "Simulation of Corrosion-Erosion of Passive Metals Using a Micro-Scale Dynamical Model," Wear, vol. 271, pp. 1404-1410, 2011. https://doi.org/10.1016/j.wear.2010.12.056

[47] F. Casesnoves, "Spinal Biomechanics Mathematical Model for Lumbar Intervertebral Ligaments," in Proc. SIAM Conference on Computational Science and Engineering, 2011, pp. 227-229.

[48] European Commission, European Textbook on Ethics in Research. EUR 24452 EN, 2010

[49] Notes, References, and Lectures. CEE SIMP Conference. Raw Materials and Circular Economy. Institute of Geology, Tallinn University of Technology, Mektory Technology Innovation Center, 2017.

[50] The European Code of Conduct for Research Integrity. Revised Edition. ALLEA, 2017

Francisco Casesnoves is Computational and Engineering/Physics Researcher. He obained M. sc. and B. sc. degrees in Physics and Applied Mathematics (University of Eastern Finland, 2001); he has M. phil. degree in Medicine and Surgery (Madrid University Medicine School, 1985), and is Phd postgraduate researcher at Tallinn University of Technology. His service to International Scientific Community commenced in 1985 with publications in medical physics, with further specialization in nonlinear optimization methods in Finland in 1997 - at the moment approximately 70 recognized international publications. His area of research is computational and mathematical nonlinear/inverse optimization. The best achievement of Casesnoves is the numerical Reuleaux method in dynamics and nonlinear optimization. This numerical reuleaux method constitutes, among others, an advance in space aerodynamics computational methods and bioengineering. Casesnoves played as defender and midfielder at Junior Madrid Football League, and as physician is supporting agnostic healthy life, public education, and all sporting activities. Casesnoves sets all his medical technology publications in Open Access, that is, accessible for free to any public health service, for the Fundamental Right to Health Care - in particular his algorithms and advances in Radiotherapy Beam Modification Devices algorithms and modelling.

Francisco Casesnoves Lopez de Haro Msc MD, Department of Mechanical Engineering, Tallinn University of Technology, Ehitahate Tee 5, Tallinn 19086, Estonia

E-mail: frcase@ttu.ee 


\section{Appendix I}

\section{Mathematical Graphical Optimization Method Demosntration of GLOBAL} MINIMUM AND MAXIMUM IN AN OBJECTIVE FUNCTION OF MODEL

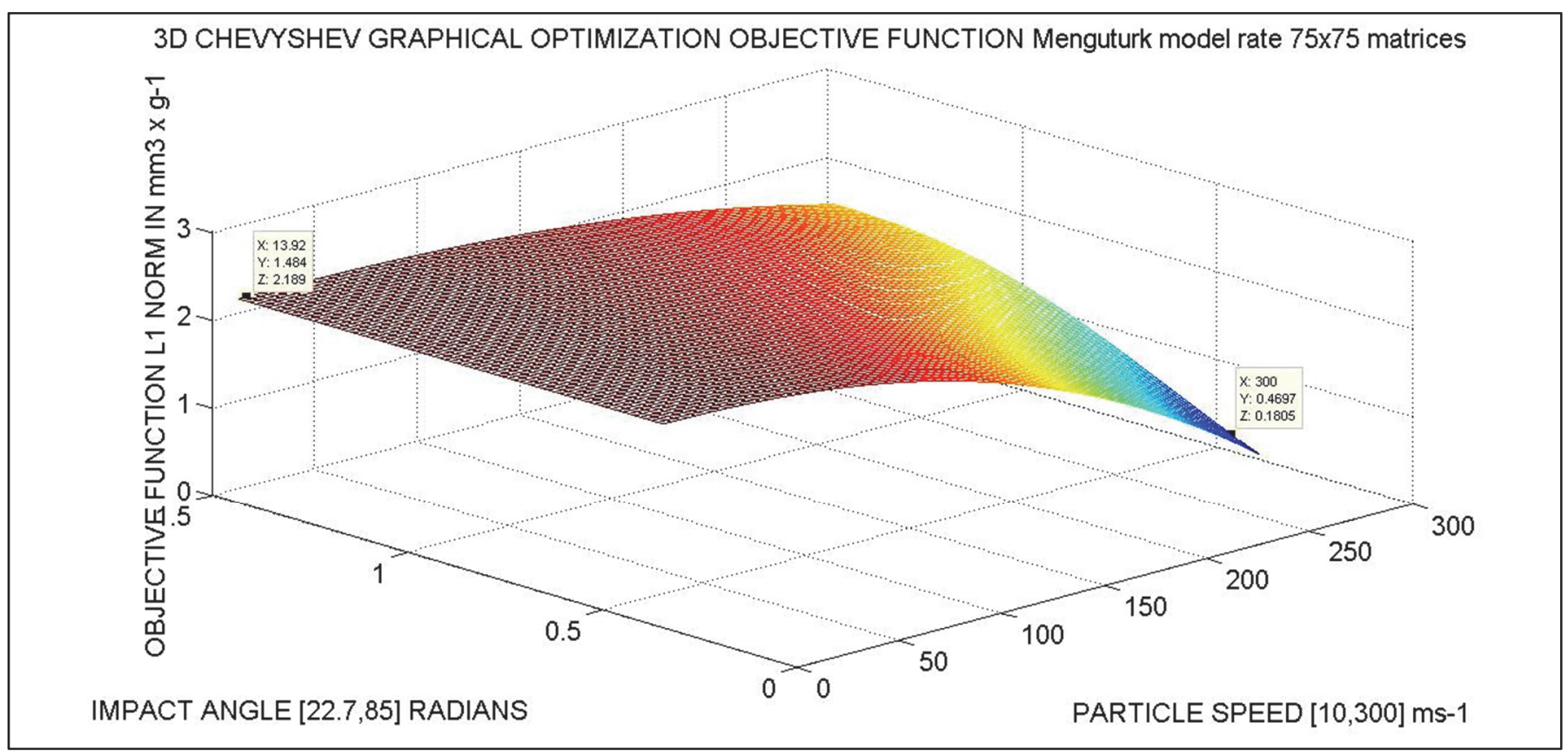

Appendix 1.1. Definite demonstration of objective function implementation in graphical optimization. This method can be extended to any model while computationally suitable for programming. In space aerodynamics, the method can be applied to fluid dynamics models.

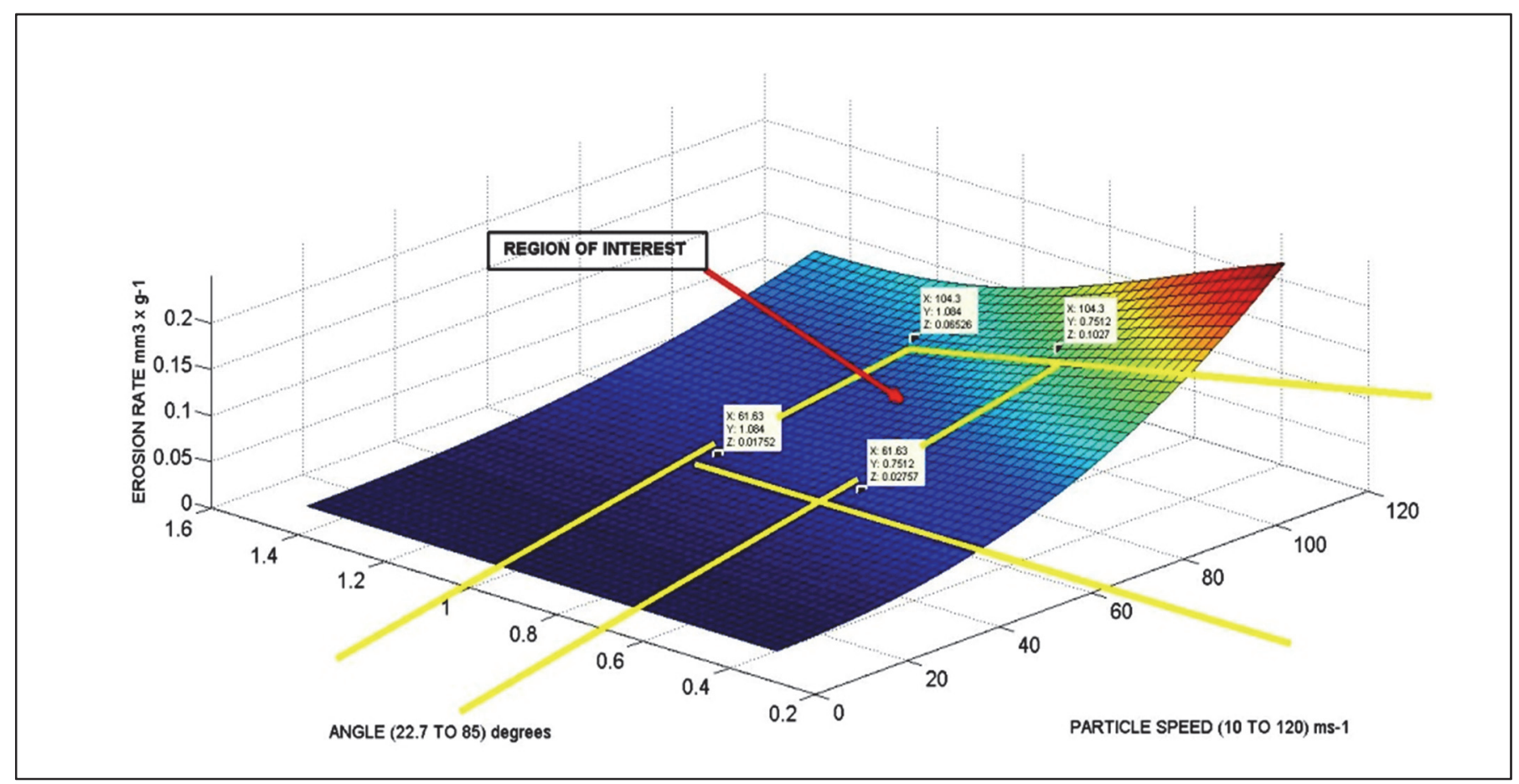

Appendix 1.2. ROI (region of interest) selection of Meguturk model with constraints. Matrices are 1000x1000, and Matlab sharpness of this image is very good, and running time is $\leq 0.5 \mathrm{~s}$ with a Linux Station 16.2 and AMD processor. Region of Interest is velocity [61.6,104.3] ms ${ }^{-1}$, angle in radians [1.0,0.7], erosion rate $[0.1,0.2] \mathrm{mm}^{3} / \mathrm{g}$. This image is intended to explain the efficiency of the graphical optimization method. For example, if at laboratory there is an apparatus that only works for these interval paramters, or if it is desired to manufacture a material with wear range and lifetime within those constraints of impact angle and particle speed that cause wear at the surface. 